\title{
Turbulent kinetic energy and sediment resuspension due to wave
} groups

Samantha Kularatne and Charitha Pattiaratchi*

School of Environmental Systems Engineering

The University of Western Australia

35 Stirling Highway, Crawley 6009, Australia

* Corresponding author

E-mail: chari.pattiaratchi@uwa.edu.au

Submitted to: Continental Shelf Research 


\section{ABSTRACT}

Wave-induced sediment resuspension in nearshore regions has been observed occurring in an event-like manner and associated with the passage of wave groups. This paper describes field measurements of turbulent velocities obtained simultaneously with suspended sediment concentration and water surface elevation from Floreat Beach, Perth, Western Australia. The data were used to study the relationship between turbulent kinetic energy (TKE) on suspension events caused by wave groups and the intermittent nature of bottom turbulence production and sediment suspension. The field measurements showed the high $T K E$ events occurred under wave crests, and sometimes under wave toughs, when the wave heights were increasing during the passage of a wave group; the TKE decreased after the maximum wave in the wave group had passed over the measurement location. High suspended sediment concentrations (sSc) and the intermittent high $T K E$ events were not related rather the higher $s S c$ events were associated with a secondary peak in the surface elevation, close to the maxima in the offshore velocity, and "burst" events in the Reynolds stress. 


\section{INTRODUCTION}

Sediment resuspension due to shoaling waves in shallow water has been observed occurring in an event-like manner, corresponding to timescales ranging from seconds (e.g. swell, wind waves) to minutes (e.g. wave groups, infragravity waves) (Brenninkmeyer, 1976; Sternberg et al., 1984; Hanes and Huntley, 1986; Osborne and Greenwood, 1993). Sediment suspension events corresponding to wave groups were also higher than at the incident wave frequency band (Clarke et al., 1982; Hanes and Huntley, 1986; Huntley and Hanes, 1987; Hanes, 1991; Vincent et al., 1991; Osborne and Greenwood, 1993; Williams et al., 2002).

Several explanations for the higher suspension events observed under wave groups have been proposed: (1) Vincent et al. (1991) attributed this phenomenon to the change in bedforms responding to the variability in the wave conditions. Here, steeper ripples present on the seabed when the wave group's smaller waves pass become less steep when the group's larger waves pass. Due to the lag in changing ripple geometry to the wave forcing, the wave groups' larger waves would encounter steeper than expected ripples and hence cause higher suspension events, which sand-laden vortices formed in the leeside of the ripples would enhance (Vincent et al., 1991); (2) Villard et al. (1999, 2000) and Villard and Osborne (2002) suggested the effect of antecedent waves could lead to coupling between antecedent and developing vortices above a rippled bed and hence cause higher suspension events. They noticed these suspension events were more pronounced when smaller waves followed larger waves. Villard et al. $(1999,2000)$ explained that uniform waves caused vortices, which cancelled each other out, but when the wave height decreased, the crest-generated vortices were stronger than those of the following trough; this slowed the crest-induced decay in vortex, retaining the sediment in suspension. These results were confirmed by Vincent and Hanes (2002); (3) Hanes and Huntley (1986) and Osborne and Greenwood (1993) related the higher suspension events due to wave groups to the persistence of turbulence which resulted in suspended sediments higher in the water column. They suggested turbulence generated at the seabed by the wave groups' larger waves lasted longer and caused higher suspension events; however, they did not measure the flow's turbulence characteristics; (4) Hay and Bowen (1994a) suggested higher suspension events observed at the wave group frequency could be the result of more than one action; that is, several mechanisms could be operating at the 
same time. They proposed vortex shedding from mega ripples enhanced interaction with the seabed during the larger waves of the wave groups, perhaps via the group-bound long wave or coherent structures in combined flow turbulence; (5) Hay and Bowen (1994b) suggested bedforms, surface-injected vortices, and the sensor support structures as possible causes for the pumping of sediments into the water column observed at the wave group frequency. Hay and Bowen (1994a) suggested, however, that keeping the sensors 5-10 diameters from the nearest support would minimise the supporting structure's influence.

Higher suspension events coinciding with the passing of wave groups have been observed in the presence (Vincent et al., 1991; Osborne and Greenwood, 1993) and absence of ripples (Hay and Bowen, 1994a; Kularatne and Pattiaratchi, in review). Although the turbulence produced during the passing of wave groups likely causes the higher suspension events, field (or numerical) studies examining the effect of turbulence on higher suspension events observed under wave groups have not appeared in the literature.

\section{Turbulent bursts}

Sediment suspension due to incident waves has been observed with intermittent spikes, which do not correspond to the wave orbital velocity (Jaffe et al., 1984; Huntley and Hanes, 1987; Hanes, 1988; Smyth and Hay, 2003), suggesting the possible influence of turbulence generated at the seabed. Intermittent coherent events of strong turbulence production and vertical transfer inside the bottom boundary layer have been observed under different flow conditions (Corino and Brodkey, 1969; Gordon, 1974; Heathershaw, 1974; Clarke et al., 1982; Thorne et al., 1984; Smyth et al., 2002; Smyth and Hay, 2003; Foster et al., 2006). The process of coherent turbulent structure formation is sometimes called the "bursting phenomenon" (Kline et al., 1967; Heathershaw, 1974; Gordon and Witting, 1977; Cantwell, 1981). These coherent events of turbulence were studied based on the Reynolds stress term (- $\left.\rho u^{\prime} w\right)$ by dividing the motions into quadrants in $u^{\prime}-w^{\prime}$ space (Kline at al., 1967; Heathershaw, 1974), where $u^{\prime}$ is the horizontal component of turbulent velocity and $w^{\prime}$ is the vertical component. Quadrants were named bursts $\left(u^{\prime}<0, w^{\prime}>0\right)$, sweeps $\left(u^{\prime}>0\right.$, $\left.w^{\prime}<0\right)$, up-accelerations $\left(u^{\prime}>0, w^{\prime}>0\right)$, and down-decelerations $\left(u^{\prime}<0, w^{\prime}<0\right)$. 
Bursts and sweeps, which contribute to positive Reynolds stress, were stronger than upaccelerations and down-decelerations (Heathershaw, 1974; Soulsby, 1983; Heathershaw and Thorne, 1985). Bursts, which consist of low-speed upward momentum transfer, and sweeps, which consist of high-speed downward momentum transfer, have been observed suspending bed sediments higher up into the water column (Sutherland, 1967; Jackson, 1976; Sumer and Oguz, 1978; Sumer and Deigaard, 1981).

All these studies involving the "bursting phenomenon", however, were conducted with steady flows or slowly oscillating flow conditions with longer periods (e.g. tides). Jackson (1976) and Sleath $(1970,1974 a, 1974 b)$ discussed the difficulties involved in examining the "bursting phenomenon" under wind-generated surface waves. Under wind-driven surface waves, the mean values of the flow parameters did not remain sensibly constant during turbulent bursts and the timescale of the largest turbulent eddies (Jackson, 1976). Further, high oscillating flows did not allow enough time to make reasonable measurements, especially of vortex formation and sudden jets in the laminar boundary layer (Sleath, 1970, 1974a, 1974b). These observations were made before modern instruments such as the acoustic/laser Doppler velocimeter (Kos'yan et al., 2003; Aagaard and Hughes, 2006), hot-film anemometers (Conley and Inman, 1992), and coherent Doppler profilers (Smyth and Hay, 2003) were developed. With these instruments, turbulence can be measured more routinely. Conley and Inman (1992) conducted high frequency velocity measurements close to the seabed under near-breaking swell waves to study the development of the fluid-granular boundary layer over permeable beds of loose sand. It should be noted, however, that the authors were not aware of any other studies conducted to examine the "bursting phenomenon" under swell waves.

Madsen (1974) reported that divers observed explosion-like events on the seabed. Hay and Bowen (1994a) suggested coherent structures in combined flow turbulence as possible causes for higher suspension events observed at wave group timescales. Clarke et al. (1982) also suggested bursts of intense turbulence associated with peak values of wave orbital velocity caused higher suspension events. These observations revealed the presence of turbulent bursts at the seabed under swell waves; therefore it is worthwhile exploring the possible presence of the "bursting phenomenon" close to the seabed. 
This paper presents a high frequency $(16 \mathrm{~Hz})$ turbulent velocity data set recorded simultaneously with the water surface elevation, cross-shore current velocity, and suspended sediment concentration close to the seabed $(0.05 \mathrm{~m})$ under shoaling, non-breaking waves. Swell-dominated conditions prevailed during the measurement period where pronounced wave groups were present.

This study's main aim was to examine the relationship between turbulent kinetic energy and the increased sediment suspension events occurring under wave groups. The turbulence measurements were analysed to examine the intermittent nature of turbulence generation and sediment suspension. Finally, an attempt was made to explore the possible signs of the "bursting phenomenon" under swell waves.

\section{METHODOLOGY}

\subsection{Field site and conditions}

Measurements were conducted at Floreat Beach, Perth, Western Australia (Figure 1), on 16 December 2003. This area experiences diurnal, microtidal conditions with a spring tidal range of $0.6 \mathrm{~m}$. Further details of the field site are given in Pattiaratchi et al. (1997). Floreat Beach is a long, straight, exposed beach, where the nearshore reefs and coastal/offshore structures do not refract the waves, and there is no offshore bar (Figure 1). The beach is steep (Figure 2) with reflective conditions, where the waves break almost on the beach face, leaving a narrow surf zone. The median grain diameter $\left(d_{50}\right)$ at the measurement site was $0.2 \mathrm{~mm}$.

The instrument station was deployed just outside the breaker line in a mean water depth of $1.2 \mathrm{~m}$ (Figure 2). The data recording started at around $1000 \mathrm{hrs}$ under swell-dominated conditions (peak period $=14 \mathrm{~s}$ ) and was terminated around $1115 \mathrm{hrs}$ with the onset of the sea breeze (the sea breeze changed the narrow-banded, swell-dominated conditions). The significant wave height was $0.9 \mathrm{~m}$ with an rms wave height of $0.65 \mathrm{~m}$. The boundary layer thickness estimated using Nielsen's (1992) method was $0.04 \mathrm{~m}$, suggesting turbulent velocity and suspended sediment concentration were measured close to or within the wave boundary layer. 


\subsection{Instrumentation}

Hydrodynamic and suspended sediment concentration measurements were collected using an array of instruments mounted on a triangular frame (SW-probe), which was developed at the University of Western Australia (Masselink and Pattiaratchi, 2001). The instruments included a Paroscientific Digiquartz pressure sensor (0.35 $\mathrm{m}$ above the bed), a Marsh-McBirney electromagnetic water current meter (model 512 OEM) (0.20 m above the bed), an optical backscatter turbidity sensor (OBS-3) (0.05 m above the bed), and a Nortek AS vector acoustic Doppler velocimeter (ADV) (with the measurement volume $0.05 \mathrm{~m}$ above the bed). The pressure sensor, electromagnetic current meter, and OBS measured water surface elevation, two-dimensional horizontal current velocities, and suspended sediment concentration, respectively, at $2 \mathrm{~Hz}$; the ADV measured the pressure and the three components of velocity at a sampling frequency of $16 \mathrm{~Hz}$.

\subsection{Data analysis techniques}

A data set of $2048 \mathrm{~s}$ duration ( $\sim 35 \mathrm{mins})$ was used for the analysis presented here. The number of data points used from the ADV was 32768, and 4096 each from the other instruments. The wave groupiness envelope was computed by low-pass-filtering the modulus of the cross-shore current velocity record at $0.02 \mathrm{~Hz}$, as List (1991) explained. Spectral analysis was conducted using digital Fourier transforms (Bendat and Piersol, 1986). The data records were divided into eight equal segments for the segment average method, with 50\% overlapping (Bendat and Piersol, 1986). A cosine taper window was applied, and the number of degrees of freedom was 32 . The $95 \%$ confidence interval calculated for all the spectra presented in this paper indicated the upper and lower confidence limits were 1.75 and 0.65 times the spectral estimates, respectively.

A difficulty with field measurements of turbulence is the separation of waves and turbulence. In regions where the mean flow is considered to be constant over the order of minutes (e.g. in the deep ocean, estuaries, etc.), the turbulent fluctuations ( $u^{\prime}, v^{\prime}$, and $\left.w^{\prime}\right)$ can be defined as the deviation from the mean or the Reynolds decomposition (Tennekes and Lumley, 1972):

$u^{\prime}(t)=u(t)-\bar{u} \quad v^{\prime}(t)=v(t)-\bar{v} \quad w^{\prime}(t)=w(t)-\bar{w}$

Trowbridge and Elgar (2001) noted it was hard to separate turbulent fluctuations ( $u^{\prime}, v^{\prime}$, and $\left.w^{\prime}\right)$ from waves because $u^{\prime}, v^{\prime}$, and $w^{\prime}$ were typically two to three orders of magnitude less energetic 
than the wave motions $(u, v$, and $w)$. The use of equation (1) to obtain turbulence measurements from a single instrument in irregular and strongly nonlinear wave conditions is also difficult (Trowbridge, 1998). Several methods, often using a high-pass filter with a specified frequency cutoff to remove orbital motions, have been proposed. This cutoff has been based on either coherence between the velocity and surface elevation signals (Thornton, 1979) or spectral slope breaks (Smyth and Hay, 2003; Scott et al., 2005). The latter method was used in this paper as outlined below.

The ADV's high frequency $(16 \mathrm{~Hz})$ velocity measurements were used to estimate turbulent velocity fluctuations (Voulgaris and Trowbridge, 1998). Time series records of turbulent velocities were used to obtain the frequency $(f)$ spectrum; the $f$ spectrum was then converted to the wave number $(k)$ spectrum following Taylor's hypothesis of “frozen turbulence” (Taylor, 1938):

$E(k)=\frac{U(z)}{2 \pi} E(f)$

where $E(k)$ is the wave number spectrum; $U(z)$ is the mean velocity at $z$ distance from the seabed; and $E(f)$ is the frequency spectrum. This is assumed to be valid when $k$ is equal to or larger than either $2 \pi / z$ or the highest significant incident wave number seen in the velocity spectrum (Huntley and Hazen, 1988). The inertial subrange corresponded to the range of wave numbers where the spectral slope was $-5 / 3$.

Turbulent energy corresponding to the inertial subrange was observed between about $30<k<120$ $\mathrm{m}^{-1}$ (Figure 3). Beyond this range, the signals seemed to contain higher noise levels and were therefore discarded (Voulgaris and Trowbridge, 1998). The inertial subrange spectral slope was 1.63 (about $-5 / 3$ ) for $u$ (Figure 3a) and 1.31 for $w$ (Figure $3 b$ ). The $-5 / 3$ spectral slope is not usually found in measurements close to the seabed (Hino et al., 1983; George et al., 1994; Smyth et al., 2002; Smyth and Hay, 2003), especially for the vertical component (Smyth et al., 2002). Turbulence generated by irregular waves over a mobile bed may be anisotropic (Smyth and Hay, 2003). The corresponding frequency spectra showed the inertial subrange was between 0.5 and 3 $\mathrm{Hz}$. 
Voulgaris and Trowbridge (1998), using a series of open channel flow tests, found the ADV could measure accurate mean flows and vertical turbulence components. They also found the noise degraded the turbulence signal in the horizontal component. In this study, however, removing the high frequency components $(>3 \mathrm{~Hz})$ overcame the noise interference.

To analyse the turbulence, the velocity signals were high-pass-filtered with a cutoff frequency of $0.5 \mathrm{~Hz}$ and low-pass-filtered with a cutoff frequency of $3 \mathrm{~Hz}$. The numerical filters were designed using fast Fourier transform techniques (Bendat and Piersol, 1986). The high-pass cutoff frequency was much higher than the incident wave frequency $(0.07 \mathrm{~Hz})$; therefore the filtering process removed most of the incident wave band energy from the original data record.

The time series of TKE was estimated using the three components of turbulent velocity $\left(u^{\prime}-\right.$ crossshore, $v^{\prime}$-longshore, and $w^{\prime}$ - vertical) at the inertial subrange:

$T K E=0.5\left(u^{\prime 2}+v^{\prime 2}+w^{\prime 2}\right)$

Turbulent Reynolds stress values were estimated by:

$\tau_{\mathrm{Re}}=-\rho u^{\prime} w^{\prime}$

where $\rho$ is the fluid density. Since no quantitative analysis of Reynolds stress was undertaken, the term $u^{\prime} w^{\prime}$ represented the turbulent Reynolds stress. Voulgaris and Trowbridge (1998) found that ADV-measured Reynolds stress values were underestimated by only $1 \%$, suggesting the ADV could measure Reynolds stress values close to the bed. 


\section{RESULTS AND DISCUSSION}

The field measurements were collected from a three-dimensional ADV current meter and an OBS sensor, both located $0.05 \mathrm{~m}$ above the seabed, to measure the turbulent velocities and suspended sediment concentration, respectively. The main assumption in the data analysis was that the sSc measured by the OBS sensor was in direct response to hydrodynamic conditions measured by the current meter (e.g. water level, velocity, and turbulence characteristics), and that the suspended sediment was advected vertically $(0.05 \mathrm{~m})$ from the seabed to reach the OBS. This means that the horizontal advection of suspended sediment into the measurement volume of the OBS could be neglected.

The time series records of the wave groupiness envelope, cross-shore current velocity, and suspended sediment concentration were compared to examine the role of wave groupiness on sediment resuspension. The time series records of the cross-shore current velocity $(u)$ at $0.2 \mathrm{~m}$ from the seabed (Figure 4a) and the suspended sediment concentration (sSC) at $0.05 \mathrm{~m}$ from the seabed (Figure 4b) revealed a correspondence between wave groups and the suspended sediment concentration (Hanes and Huntley, 1986; Huntley and Hanes, 1987; Hanes, 1991; Vincent et al., 1991; Osborne and Greenwood, 1993).

The results of the spectral analysis of cross-shore velocity, $u(0.2 \mathrm{~m}$ from the seabed), and the suspended sediment concentration, ssc $(0.05 \mathrm{~m}$ from the seabed $)$, time series are presented in Figure 5. It is widely accepted the horizontal velocities under oscillatory flow in shallow water remain constant over the depth (Huntley and Hanes, 1987; Aagaard and Greenwood, 1995; Foote et al., 1998). The auto-spectrum of $u$ showed a dominant peak at $0.07 \mathrm{~Hz}(\sim 14 \mathrm{~s})$ and swelldominated conditions (Figure 5a). Minor peaks were observed at the swell frequency band first harmonic and at low frequencies. The auto-spectrum of ssc showed a dominant peak at low frequencies, confirming higher sediment concentrations due to wave groups (Figure 5b).

The co-spectrum between $u$ and ssc (Figure 5c) agreed with Huntley and Hanes's (1987) original findings for shoaling, non-breaking waves in shallow water: onshore sediment flux was at the incident frequency band and offshore sediment flux was at low frequencies, corresponding to wave 
groups. The onshore flux at the incident band was attributed to the increased wave/velocity skewness towards the wave propagation direction (Doering and Bowen, 1988; Osborne and Greenwood, 1992); offshore flux at low frequencies was due to the combined action of wave groups and the group-bound long wave (Larsen, 1982; Shi and Larsen, 1984). A small offshore sediment flux component was also present at the incident frequency band first harmonic.

The relationship between the hydrodynamic parameters (surface elevation, cross-shore currents, and turbulent kinetic energy) and sediment suspension during a single wave group from 600 to 900 s was examined (Figure 6). At the start of the time series, the mean $T K E$ was negligible (Figure $6 \mathrm{~d}$ - thick line) and increased as the wave group passed over the measurement point, especially when the incident wave height was increasing (Figures 6a and 6d). The mean TKE then decreased while the incident wave height stayed almost constant. Similarly, towards the end of the wave group, the mean TKE increased again with a change in incident wave height. The mean suspended sediment concentration followed a similar pattern: increased mean suspended sediment concentration values were observed with increasing mean TKE (thick lines in Figures $6 \mathrm{~d}$ and $6 \mathrm{e}$ ).

The same pattern was observed for the wave group that occurred between 950 and $1100 \mathrm{~s}$ (Figure 7). At first, there was almost no TKE, and no suspended sediment. With the increase in the incident wave height, as the wave group passed over the measurement point (Figure 7a), the mean $T K E$ increased (Figure 7d), followed by an increase in the mean suspended sediment concentration (Figure 7e). The same trend was seen with the wave group that spanned between 80 and $240 \mathrm{~s}$ (Figure 8 ) and other wave groups in the data record. These observations suggested that changes in the incident wave height (or energy) as wave groups passed over the measurement point caused higher $T K E$ when the incident wave height was changing (increasing) than when it was constant, irrespective of the magnitude of the wave height.

The individual sediment resuspension events were related to the measurements of water elevation and cross-shore velocity, and showed a consistent pattern. The elevation time series showed the presence of a secondary peak (a change in the rate of water level decrease) after the passage of a wave crest and before reaching the mean water level (Figures 6a, 7a, and 8a). This feature was most likely due to the presence of the first harmonic of the incident waves (Figure 5a), as it was 
often seen in the surface elevation records (Figures $6 a, 7 a$, and 8a). The time series of the crossshore currents and SSC showed the higher sSc events in the wave group coincided with the secondary peak in the water surface elevation, which occurred at the same time as the local maximum in the offshore velocity (Figures $6 \mathrm{~b}, 7 \mathrm{~b}$, and $8 \mathrm{~b}$ ); that is, discrete sediment resuspension events occurred only on the offshore phase of the wave cycle where there was a change in the rate of water level decrease (the secondary peak) and a local maximum in offshore velocity. In contrast, the high, immediate $T K E$ events were usually associated with either a wave crest or a wave trough, which Foster et al. (2006) also observed. Thus the sediment resuspension and immediate (high) TKE events were not related. This was apparent in Figure 8, where the peaks in the $T K E$, which occurred at around $100 \mathrm{~s}$ because of the increasing wave heights in the wave group (see above), were not associated with sediment resuspension events.

At the incident wave scale, the turbulent Reynolds stress $\left(u^{\prime} w^{\prime}\right)$ showed intermittent bursts, which sometimes seemed to coincide with the passage of wave crests and the onshore velocity maxima (Figure 8). The suspended sediment concentration also showed an intermittent structure, which coincided with the secondary peak in the surface elevation and the maxima in the offshore flow velocity (see above). This was in contrast to Foster et al.'s (2006) findings, in which the intermittent sediment suspension was biased towards the flow's onshore decelerating phase.

The observed intermittent Reynolds stress $\left(u^{\prime} w^{\prime}\right)$, however, did not always cause suspension events (see Figures 7 and 8), and this could be related to the "bursting phenomenon" described in Section 1. The intermittent nature of the turbulent bursts suggested that higher Reynolds shear stress values were usually observed under burst and sweep events (negative $u^{\prime} w^{\prime}$ ) than under upacceleration and down-deceleration events (positive $u^{\prime} w^{\prime}$ ) (Figures 6c, 7c, and 8c). Major burst and sweep events accounted for only 3 out of $60 \mathrm{~s}$ (5\%), but contributed about $60 \%$ of the TKE (Figure 9). Similar results have been observed under flow conditions that were different from swell waves (Gordon, 1974; Heathershaw, 1974; Soulsby, 1983). The Reynolds stress time series for short sections of the data was used to identify burst and sweep events and was related to the suspended sediment concentration (Figures 9 and 10). Here it was apparent the high ssc events were associated with burst events $\left(u^{\prime}<0, w^{\prime}>0\right)$ rather than sweep $\left(u^{\prime}>0, w^{\prime}<0\right)$ events. Similar results have been found for tidal environments (Soulsby, 1983; Heathershaw and Thorne, 1985). 
One of the main limitations of the current data set was the spatial coverage of the observations, where measurements were made only at a single point; thus the data interpretation was based on the assumptions listed at the start of this section. However, it is important to examine the validity of the assumptions, especially the horizontal advection of suspended sediment to the measurement region from the turbulence generated outside the measurement region. The data showed the high ssc events were associated with specific hydrodynamic events associated with the passage of a wave group, i.e. the secondary peak in water elevation and maxima in offshore velocity. This result suggested that although suspended sediment may have been advected into the measurement region, the fact that resuspension occurred only under specific hydrodynamic conditions meant uniform conditions were likely in the immediate vicinity of the measurement location.

In summary, the high resolution field data obtained from a swell-dominated environment with a pronounced wave group structure showed high TKE events occurred under wave crests, and sometimes under wave troughs, when the wave height was increasing with the passage of a wave group. The sediment suspension and intermittent TKE events were not related. High suspended sediment concentrations were associated with a secondary peak in the surface elevation, close to the maxima in the offshore velocity, and were associated with "burst" events in the Reynolds stress. 


\section{CONCLUSIONS}

A set of high frequency $(16 \mathrm{~Hz})$ turbulent velocity measurements obtained simultaneously with suspended sediment concentration, cross-shore current velocity, and water surface elevation at Floreat Beach (Perth, Western Australia) was analysed to examine the effects of turbulence on wave group-induced higher suspension events, the intermittent nature of bottom turbulence production and sediment suspension, and the "bursting phenomenon" (Heathershaw, 1974).

The field data showed the turbulent kinetic energy (TKE) increased with the increase in incident wave height associated with the passage of a wave group. The TKE was higher when the incident wave height was increasing than when it was constant, irrespective of the wave height magnitude. High TKE events were associated with wave crests and sometimes with wave troughs. The sediment suspension and intermittent TKE events were not related. Short but intense burst and sweep events, suggesting the presence of the "bursting phenomenon", dominated the Reynolds stress term $\left(u^{\prime} w^{\prime}\right)$. High suspended sediment concentration events were associated with bursts, which occurred during a secondary peak in the water elevation and maximum in the offshore velocity.

\section{ACKNOWLEDGEMENTS}

We acknowledge the award of an International Postgraduate Research Scholarship/University Postgraduate Award (to S.K.) and Ruth Gongora-Mesas for her help in preparing the final manuscript. 


\section{REFERENCES}

Aagaard, T., and Greenwood, B. (1995). Suspended sediment transport and morphological response on a dissipative beach. Continental Shelf Research, 15 (9): 1061-1086.

Aagaard, T., and Hughes, M.G. (2006). Sediment suspension and turbulence in the swash zone of dissipative beaches. Marine Geology, 228: 117-135.

Bendat, J.S., and Piersol, A.G. (1986). Random data: analysis and measurement procedures. Wiley-Interscience.

Brenninkmeyer, B.M. (1976). In situ measurements of rapidly fluctuating, high sediment concentrations. Marine Geology, 20: 117-128.

Cantwell, B.J. (1981). Organized motion in turbulent flow. Annual Review of Fluid Mechanics, 13: $457-515$.

Clarke, T.L., Lesht, R.A., Young, R.A., Swift, D.J.P., and Freeland, G.L. (1982). Sediment resuspension by surface-wave action: an examination of possible mechanisms. Marine Geology, 49: 43-59.

Conley, D.C., and Inman, D.L. (1992). Field observations of the fluid-granular boundary layer under near-breaking waves. Journal of Geophysical Research, 97 (C6): 9631-9643.

Corino, E.R., and Brodkey, R.S. (1969). A visual investigation of the wall region in turbulent flow. Journal of Fluid Mechanics, 37: 1-30.

Doering, J.C., and Bowen, A.J. (1988). Wave-induced flow and nearshore suspended sediment. Coastal engineering, Proceedings of the twenty-first international coastal engineering conference, ASCE, Malaga, pp. 1452-1463.

Foote, Y., Russell, P.E., Huntley, D.A., and Sims, P. (1998). Energetics prediction of frequencydependent suspended sand transport rates on a macrotidal beach. Earth Surface Processes and Landforms, 23: 927-941.

Foster, D.L., Beach, R.A., and Holman, R.A. (2006). Turbulence observations of the nearshore wave bottom boundary layer. Journal of Geophysical Research, 111 (C04011): doi:10.1029/2004JC002838.

George, R., Flick, R.E., and Guza, R.T. (1994). Observations of turbulence in the surf zone. Journal of Geophysical Research, 99: 801-810.

Gordon, C.M. (1974). Intermittent momentum transport in a geophysical boundary layer. Nature, 248: $392-394$.

Gordon, C.M., and Witting, J. (1977). Turbulent structure in a benthic boundary layer. In: J.C.J. Nihoul (editor), Bottom turbulence. Elsevier, Amsterdam. 
Hanes, D.M. (1988). Intermittent sediment suspension and its implications to sand tracer dispersal in wave-dominated environments. Marine Geology, 81: 175-183.

Hanes, D.M. (1991). Suspension of sand due to wave groups. Journal of Geophysical Research, 96 (C5): 8911-8915.

Hanes, D.M., and Huntley, D.A. (1986). Continuous measurements of suspended sand concentration in a wave dominated nearshore environment. Continental Shelf Research, 6 (4): 585-596.

Hay, A.E., and Bowen, A.J. (1994a). Coherence scales of wave-induced suspended sand concentration fluctuations. Journal of Geophysical Research, 99: 12749-12766.

Hay, A.E., and Bowen, A.J. (1994b). Space-time variability of sediment suspension in the nearshore zone. Coastal dynamics '94, Proceedings of an international conference on the role of the large scale experiments in coastal research, ASCE, Barcelona, pp. 962-975.

Heathershaw, A.D. (1974). "Bursting" phenomena in the sea. Nature, 248: 394-395.

Heathershaw, A.D., and Thorne, P.D. (1985). Sea-bed noises reveal role of turbulent bursting phenomenon in sediment transport by tidal currents. Nature, 316 (6026): 339-342.

Hino, M., Kashiwayanagi, M., Nakayama, A., and Hara, T. (1983). Experiments on the turbulence statistics and the structure of a reciprocating oscillatory flow. Journal of Fluid Mechanics, 131: 363-400.

Huntley, D.A., and Hanes, D.M. (1987). Direct measurement of suspended sediment transport. Coastal sediments '87, Proceedings of a specialty conference on advances in understanding of coastal sediment processes, ASCE, New Orleans, Louisiana, pp. 723-737.

Huntley, D.A., and Hazen, D.G. (1988). Seabed stresses in combined wave and steady flow conditions on the Nova Scotia continental shelf: field measurements and predictions. Journal of Physical Oceanography, 18 (2): 347-362.

Jackson, R.G. (1976). Sedimentological and fluid-dynamic implications of the turbulent bursting phenomenon in geophysical flows. Journal of Fluid Mechanics, 77 (3): 531-560.

Jaffe, B.E., Sternberg, R.W., and Sallenger, A.H. (1984). The role of suspended sediment in shorenormal beach profile changes. Coastal engineering (1984), Nineteenth coastal engineering conference: proceedings of the international conference, ASCE, Houston, Texas, pp. 19831996.

Kline, S.J., Reynolds, W.C., Schraub, F.A., and Runstadler, P.W. (1967). The structure of turbulent boundary layers. Journal of Fluid Mechanics, 30: 741-773.

Kos'yan, R., Kunz, H., Kuznetsov, S., Podymov, I., and Pykhov, N. (2003). Research of the basic mechanism of sand suspension by irregular waves. Proceedings of the sixth international 
conference on coastal and port engineering in developing countries (COPEDEC VI), Lanka Hydraulic Institute, Colombo, Sri Lanka.

Kularatne, S.R., and Pattiaratchi, C. (in review). Factors influencing cross-shore sediment flux in the frequency domain. Continental Shelf Research.

Larsen, L.H. (1982). A new mechanism for seaward dispersion of midshelf sediments. Sedimentology, 29: 279-283.

List, J.H. (1991). Wave groupiness variations in the nearshore. Coastal Engineering, 15: 475-496.

Madsen, O.S. (1974). Stability of a sand bed under breaking waves. Proceedings of the fourteenth coastal engineering conference, ASCE, pp. 776-794.

Masselink, G., and Pattiaratchi, C.B. (2001). Seasonal changes in beach morphology along the sheltered coastline of Perth, Western Australia. Marine Geology, 172: 243-263.

Nielsen, P. (1992). Coastal bottom boundary layers and sediment transport. World Scientific, Singapore, $324 \mathrm{pp}$.

Osborne, P.D., and Greenwood, B. (1992). Frequency dependent cross-shore suspended sediment transport. 2. A barred shoreface. Marine Geology, 106: 25-51.

Osborne, P.D., and Greenwood, B. (1993). Sediment suspension under waves and currents: time scales and vertical structure. Sedimentology, 40: 599-622.

Pattiaratchi, C.B., Hegge, B., Gould, J., and Eliot, I. (1997). Impact of sea-breeze activity on nearshore and foreshore processes in southwestern Australia. Continental Shelf Research, 17: $1539-1560$.

Scott, C.P., Cox, D.T., Shin, S., and Clayton, N. (2005). Estimates of surf zone turbulence in a large-scale laboratory flume. In J. McKee Smith (editor), Coastal engineering 2004, Proceedings of the twenty-ninth international coastal engineering conference. World Scientific Publishing Co., New Jersey, pp. 379-391.

Shi, N.C., and Larsen, L.H. (1984). Reverse sediment transport induced by amplitude-modulated waves. Marine Geology, 54: 181-200.

Sleath, J.F.A. (1970). Velocity measurements close to the bed in a wave tank. Journal of Fluid Mechanics, 42: 111-123.

Sleath, J.F.A. (1974a). Stability of laminar flow at seabed. Journal of Waterway, Port, Coastal, and Ocean Engineering, 100: 105-122.

Sleath, J.F.A. (1974b). Velocities above rough bed in oscillatory flow. Journal of Waterway, Port, Coastal, and Ocean Engineering, 100: 287-304. 
Smyth, C., and Hay, A.E. (2003). Near-bed turbulence and bottom friction during SandyDuck97. Journal of Geophysical Research, 108 (C6): 3197, doi:10.1029/2001JC000952.

Smyth, C., Hay, A.E., and Zedel, L. (2002). Coherent Doppler profiler measurements of near-bed suspended sediment fluxes and the influence of bed forms. Journal of Geophysical Research, 107 (C8): doi:10.1029/2000JC000760.

Soulsby, R.L. (1983). The bottom boundary layer of shelf seas. In: B. Johns (editor), Physical oceanography of coastal and shelf seas. Elsevier, Amsterdam, pp. 189-266.

Sternberg, R.W., Shi, N.C., and Downing, J.P. (1984). Field investigations of suspended sediment transport in the nearshore zone. Coastal engineering (1984), Nineteenth coastal engineering conference: proceedings of the international conference, ASCE, Houston, Texas, pp. 1782-1798.

Sumer, B.M., and Deigaard, R. (1981). Particle motions near the bottom in turbulent flow in an open channel. Part 2. Journal of Fluid Mechanics, 109: 311-337.

Sumer, B.M., and Oguz, B. (1978). Particle motions near the bottom in turbulent flow in an open channel. Journal of Fluid Mechanics, 86: 109-127.

Sutherland, A.J. (1967). Proposed mechanism for sediment entrainment by turbulent flows. Journal of Geophysical Research, 72: 6138-6194.

Taylor, G.I. (1938). The spectrum of turbulence. Proceedings of the Royal Society A: Mathematical, Physical and Engineering Sciences, 164: 476-490.

Tennekes, H., and Lumley, J.L. (1972). A first course in turbulence. MIT Press, Cambridge, MA.

Thorne, P.D., Heathershaw, A.D., and Troiano, L. (1984). Acoustic detection of seabed gravel movement in turbulent tidal currents. Marine Geology, 54 (3-4): M43-M48.

Thornton, E.B. (1979). Energetics of breaking waves within the surf zone. Journal of Geophysical Research, 84: 4931-4938.

Trowbridge, J.H. (1998). On a technique for measurement of turbulent shear stress in the presence of surface waves. Journal of Atmospheric and Oceanic Technology, 15: 290-298.

Trowbridge, J.H., and Elgar, S. (2001). Turbulence measurements in the surf zone. Journal of Physical Oceanography, 31: 2403-2417.

Villard, P.V., and Osborne, P.D. (2002). Visualization of wave-induced suspension patterns over two-dimensional bedforms. Sedimentology, 49: 363-378.

Villard, P.V., Osborne, P.D., and Vincent, C.E. (1999). Influence of wave groups on sand resuspension over bedforms in a large scale wave flume. In: N.C. Kraus and W.G. McDougal, Coastal sediments 1999, Proceedings of the fourth international symposium on 
coastal engineering and science of coastal sediment processes. American Society of Civil Engineers, Reston, VA, pp. 367-376.

Villard, P.V., Osborne, P.D., and Vincent, C.E. (2000). Influence of wave groups on SSC patterns over vortex ripples. Continental Shelf Research, 20: 2391-2410.

Vincent, C.E., and Hanes, D.M. (2002). The accumulation and decay of near-bed suspended sand concentration due to waves and wave groups. Continental Shelf Research, 22: 1987-2000.

Vincent, C.E., Hanes, D.M., and Bowen, A.J. (1991). Acoustic measurements of suspended sand on the shoreface and the control of concentration by bed roughness. Marine Geology, 96: $1-18$.

Voulgaris, G., and Trowbridge, J.H. (1998). Evaluation of the acoustic Doppler velocimeter (ADV) for turbulence measurements. Journal of Atmospheric and Oceanic Technology, 15: 272-289.

Williams, J.J., Rose, C.P., and Thorne, P.D. (2002). Role of wave groups in resuspension of sandy sediments. Marine Geology, 183 (1-4): 17-29. 


\section{FIGURE CAPTIONS}

Figure 1: $\quad$ Location map (Floreat Beach, Perth, Western Australia).

Figure 2: $\quad$ Instrument deployment location and beach profile.

Figure 3: Wave number spectra of: a) horizontal cross-shore velocity $(u)$; b) vertical velocity $(w)$.

Figure 4: Time series records of: a) cross-shore current velocity $(u)$; b) suspended sediment concentration (sSc); and c) turbulent kinetic energy (TKE). Thick, solid lines show the envelope function of $u$ (a), low-pass-filtered sSc (b), and low-pass-filtered TKE (c), respectively.

Figure 5: Results of the spectral analysis between the cross-shore velocity, $u$, and the suspended sediment concentration, $c$. a) Auto-spectrum of $u$; b) auto-spectrum of $s s c$; and c) $u$-ssc co-spectrum in $\left(g l^{-1}\right)\left(m s^{-1}\right) H z^{-1}$.

Figure 6: $\quad$ Time series records of: (a) water surface elevation, $\eta$ (solid line), and envelope function of $\eta$ (thick, solid line); (b) cross-shore velocity (u); (c) turbulent Reynolds stress $\left(u^{\prime} w^{\prime}\right)$; (d) turbulent kinetic energy (TKE); and (e) suspended sediment concentration (ssc) for a wave group observed between 600 and 900 s. Note: the maximum voltage setting for the OBS was insufficient to capture the maximum suspended sediment concentrations that occurred between 700 and $730 \mathrm{~s}$.

Figure 7: Time series records of: (a) water surface elevation, $\eta$ (solid line), and envelope function of $\eta$ (thick, solid line); (b) cross-shore velocity (u); (c) turbulent Reynolds stress $\left(u^{\prime} w^{\prime}\right)$; (d) turbulent kinetic energy (TKE); and (e) suspended sediment concentration (sSc) for a wave group observed between 950 and $1100 \mathrm{~s}$. 
Figure 8: $\quad$ Time series records of: (a) water surface elevation, $\eta$ (solid line), and envelope function of $\eta$ (thick, solid line); (b) cross-shore velocity (u); (c) turbulent Reynolds stress $\left(u^{\prime} w^{\prime}\right)$; (d) turbulent kinetic energy (TKE); and (e) suspended sediment concentration (sSc) for a wave group observed between 80 and $240 \mathrm{~s}$.

Figure 9: Time series records of: (a) turbulent Reynolds stress ( $\left.u^{\prime} w^{\prime}\right)$; and (b) suspended sediment concentration (ssc) between 730 and $790 \mathrm{~s}$.

Figure 10: Time series records of: (a) turbulent Reynolds stress ( $\left.u^{\prime} w^{\prime}\right)$; and (b) suspended sediment concentration (ssc) between 950 and $1100 \mathrm{~s}$. 


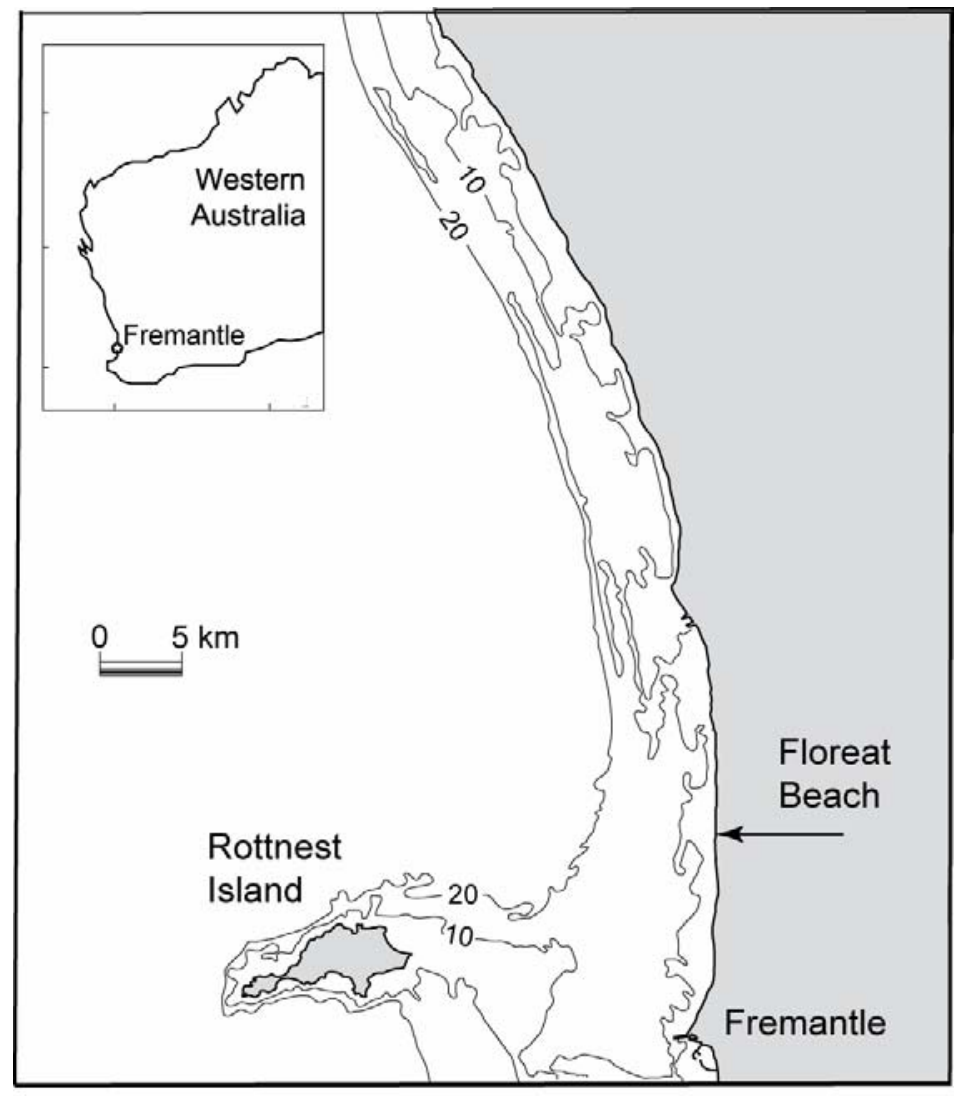

Figure 1. Location map (Floreat Beach, Perth, Western Australia).

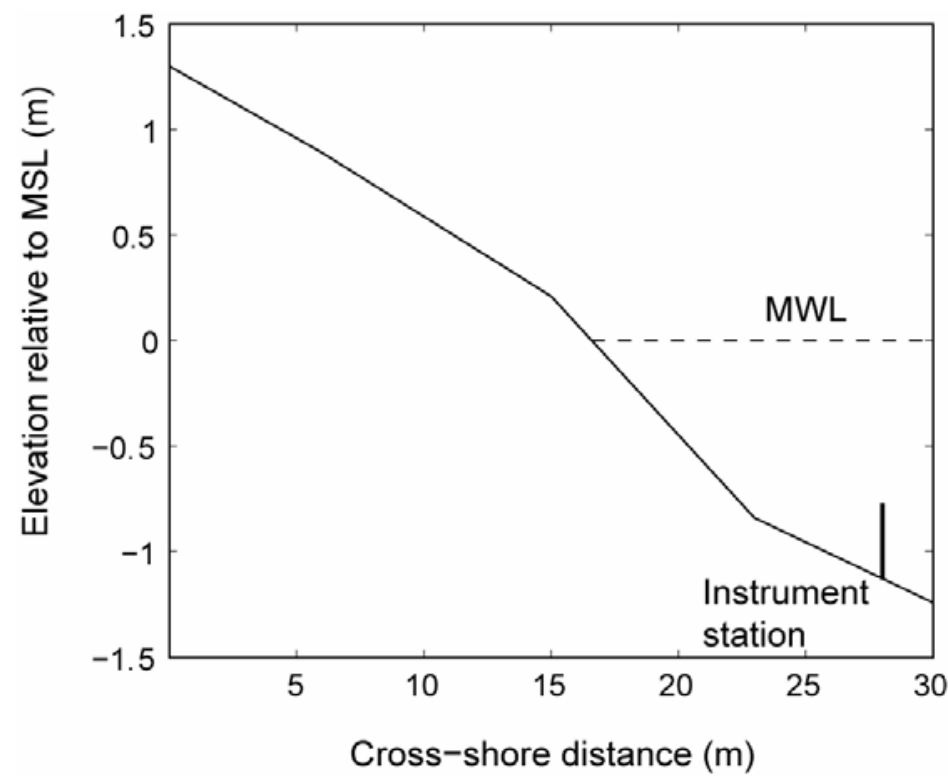

Figure 2. Instrument deployment location and beach profile. 

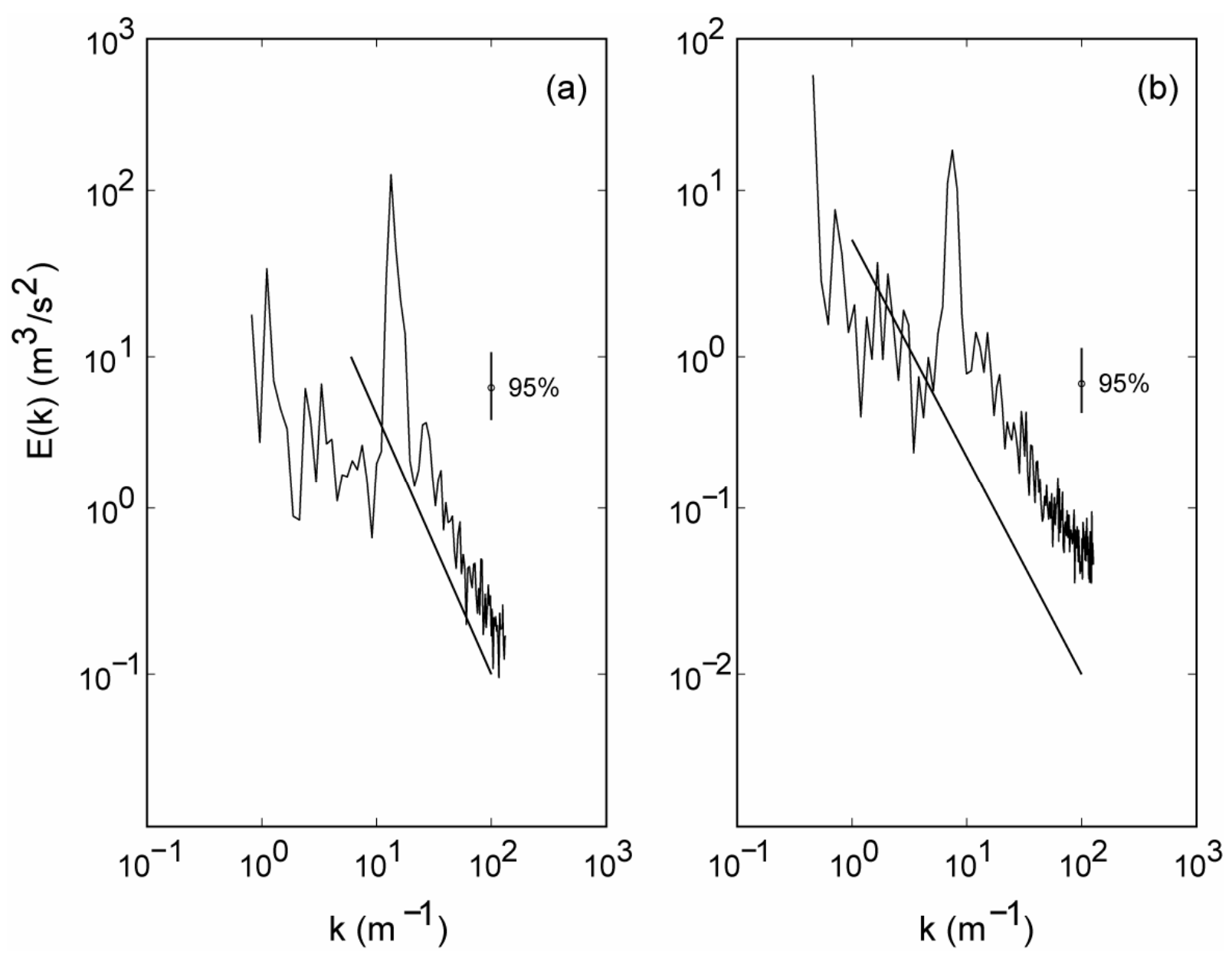

Figure 3. Wave number spectra of: (a) horizontal cross-shore velocity $(u)$; (b) vertical velocity $(w)$. 

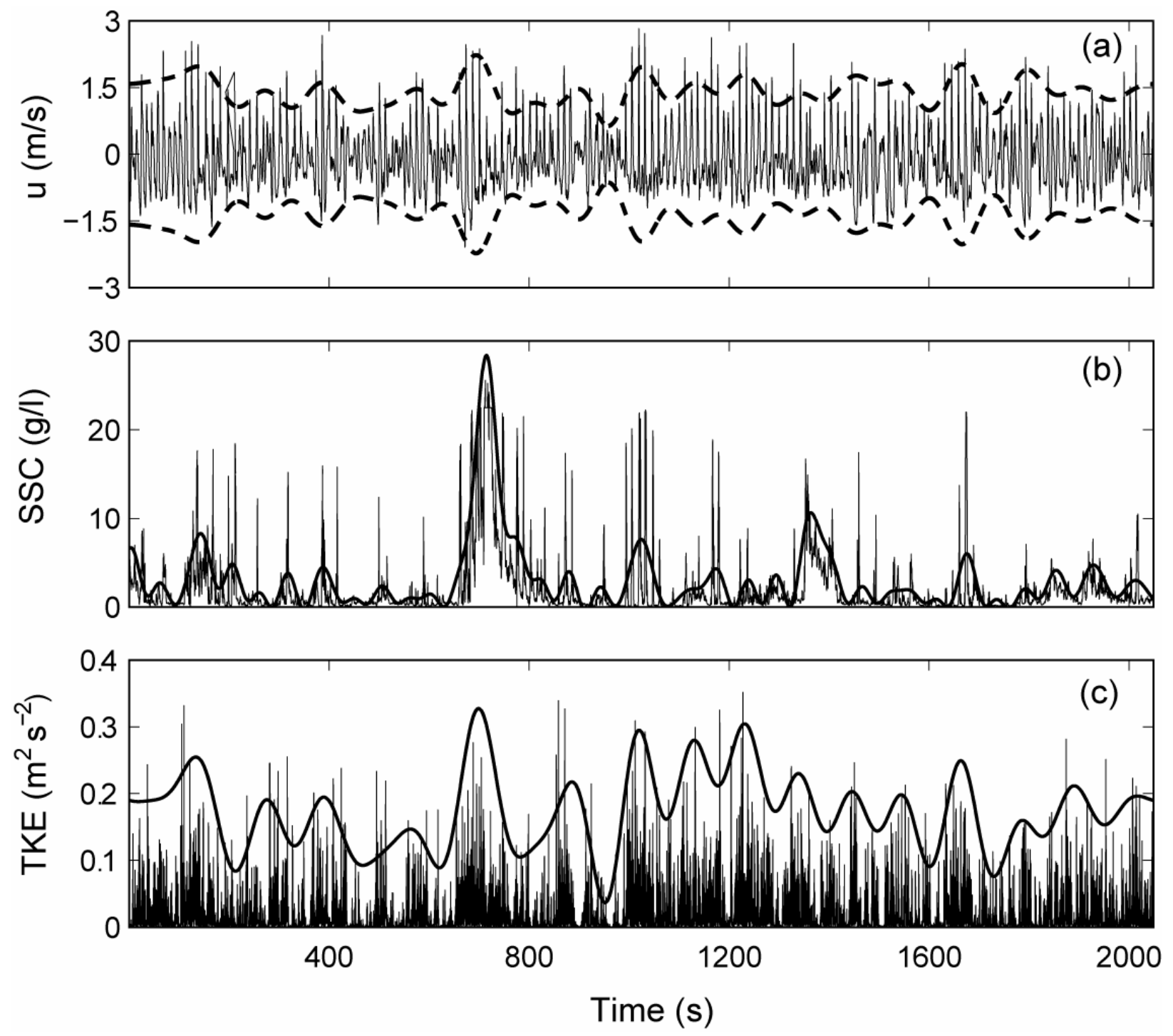

Figure 4. Time series records of: (a) cross-shore current velocity ( $u$ ); (b) suspended sediment concentration (ssc); and (c) turbulent kinetic energy (TKE). Thick, solid lines show the envelope function of $u$ (a), low-pass-filtered ssc (b), and low-pass-filtered TKE (c), respectively. 

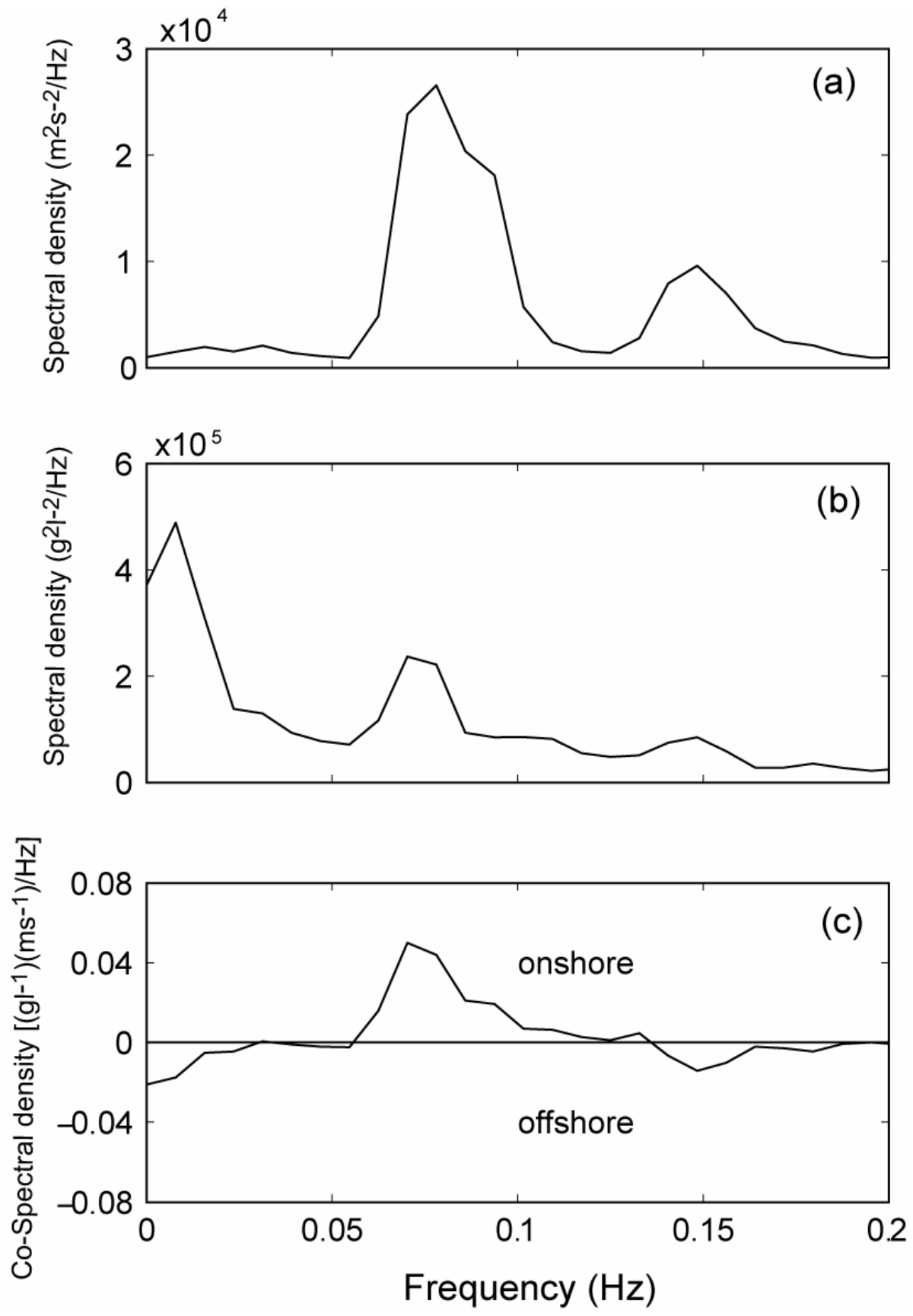

Figure 5. Results of the spectral analysis between the cross-shore velocity, $u$, and the suspended sediment concentration, ssc. (a) Auto-spectrum of $u$; (b) auto-spectrum of $s s c$; and (c) $u$-ssc cospectrum in $\left(g l^{-1}\right)\left(\mathrm{ms}^{-1}\right) \mathrm{Hz}^{-1}$. 

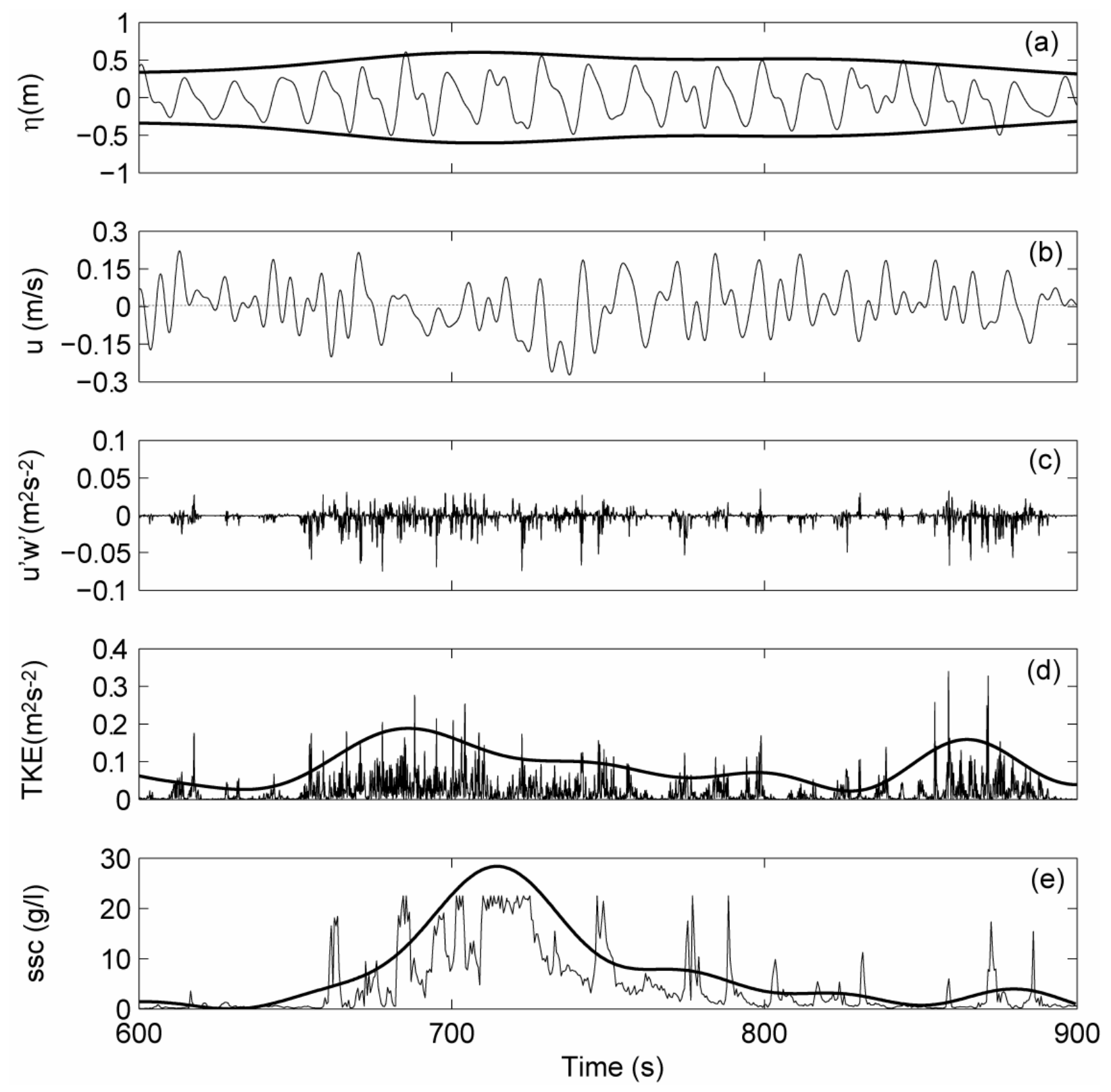

Figure 6. Time series records of: (a) water surface elevation, $\eta$ (solid line), and envelope function of $\eta$ (thick solid line); (b) cross-shore velocity (u); (c) turbulent Reynolds stress ( $\left.u^{\prime} w^{\prime}\right)$; (d) turbulent kinetic energy (TKE); and (e) suspended sediment concentration (sSc) for a wave group observed between 600 and 900 s. Note: the maximum voltage setting for the OBS was insufficient to capture the maximum suspended sediment concentrations that occurred between 700 and $730 \mathrm{~s}$. 

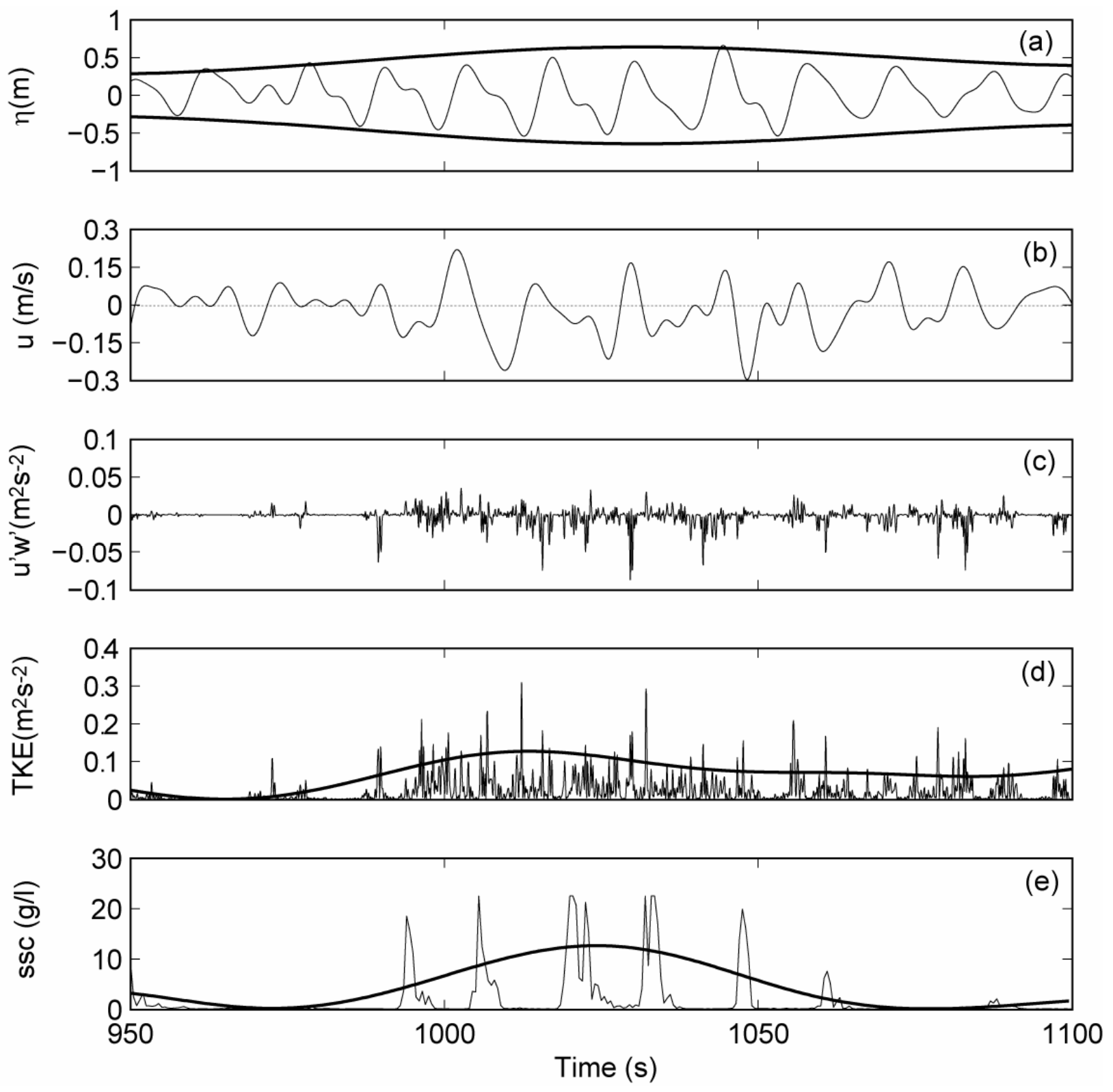

Figure 7. Time series records of: (a) water surface elevation, $\eta$ (solid line), and envelope function of $\eta$ (thick solid line); (b) cross-shore velocity (u); (c) turbulent Reynolds stress ( $\left.u^{\prime} w^{\prime}\right)$; (d) turbulent kinetic energy (TKE); and (e) suspended sediment concentration (sSc) for a wave group observed between 950 and $1100 \mathrm{~s}$. 

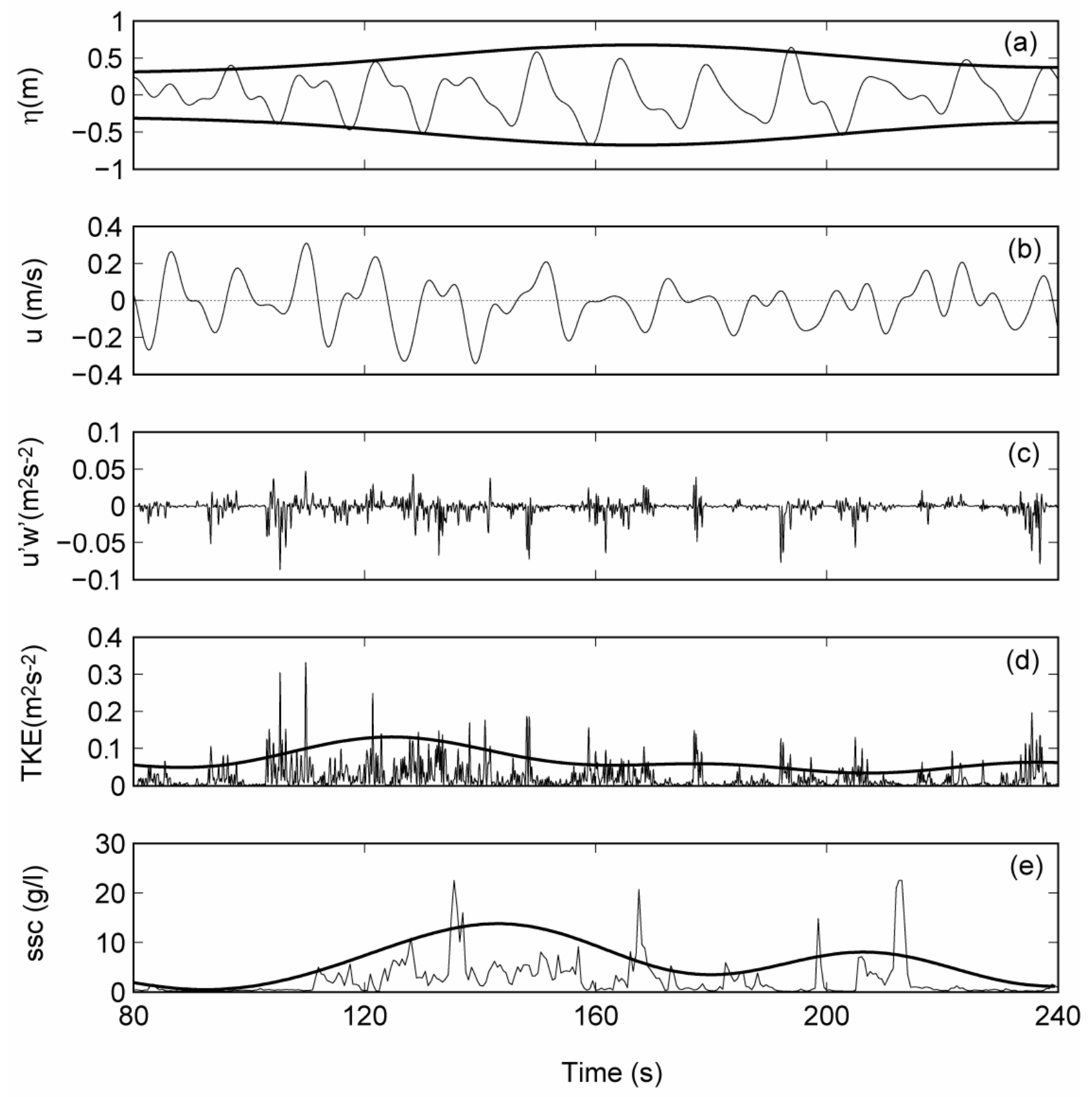

Figure 8. Time series records of: (a) water surface elevation, $\eta$ (solid line), and envelope function of $\eta$ (thick, solid line); (b) cross-shore velocity (u); (c) turbulent Reynolds stress ( $\left.u^{\prime} w^{\prime}\right)$; (d) turbulent kinetic energy (TKE); and (e) suspended sediment concentration (ssc) for a wave group observed between 80 and $240 \mathrm{~s}$. 

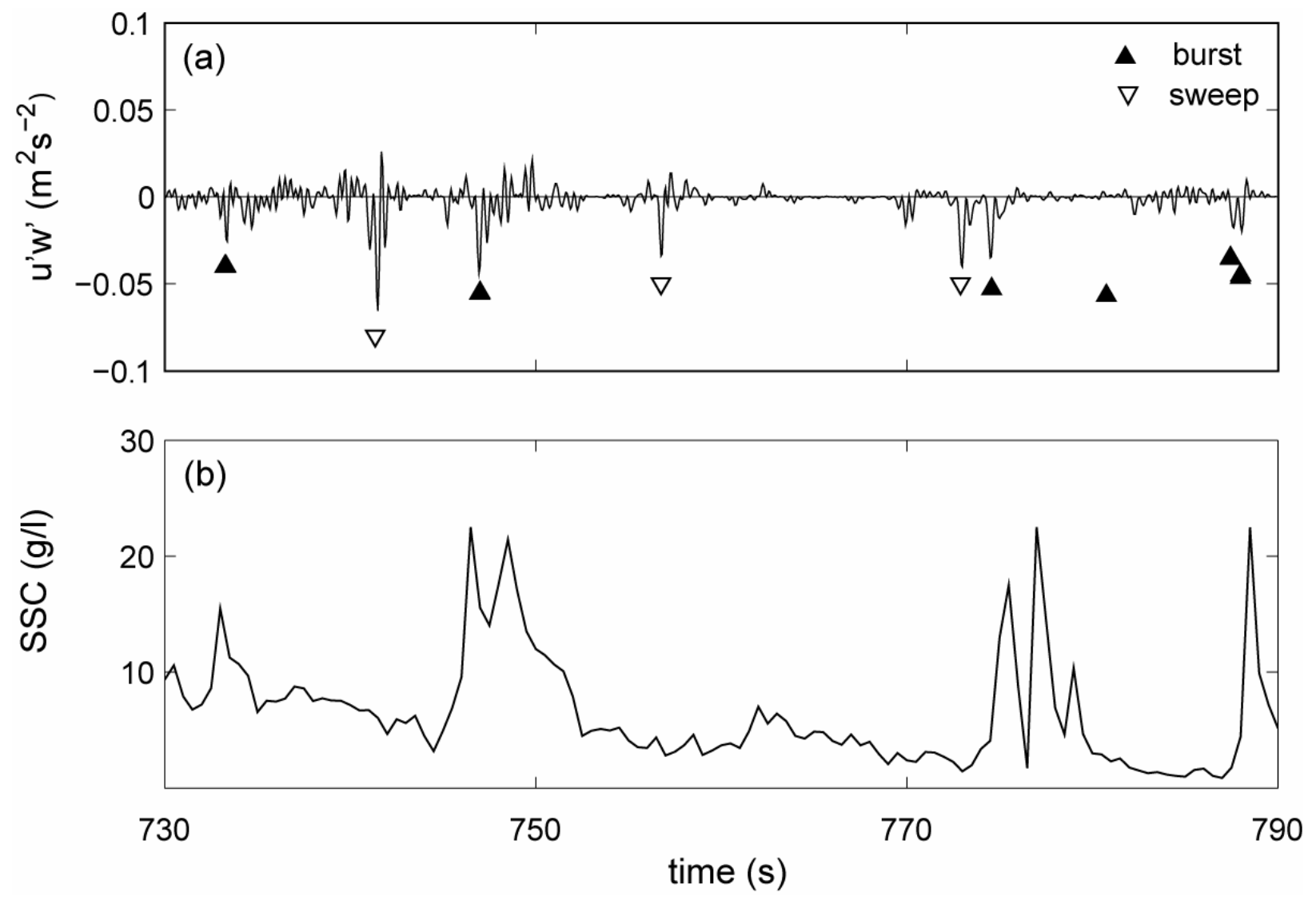

Figure 9. Time series records of: (a) turbulent Reynolds stress ( $\left.u^{\prime} w^{\prime}\right)$; and (b) suspended sediment concentration (sSc) between 730 and $790 \mathrm{~s}$. 

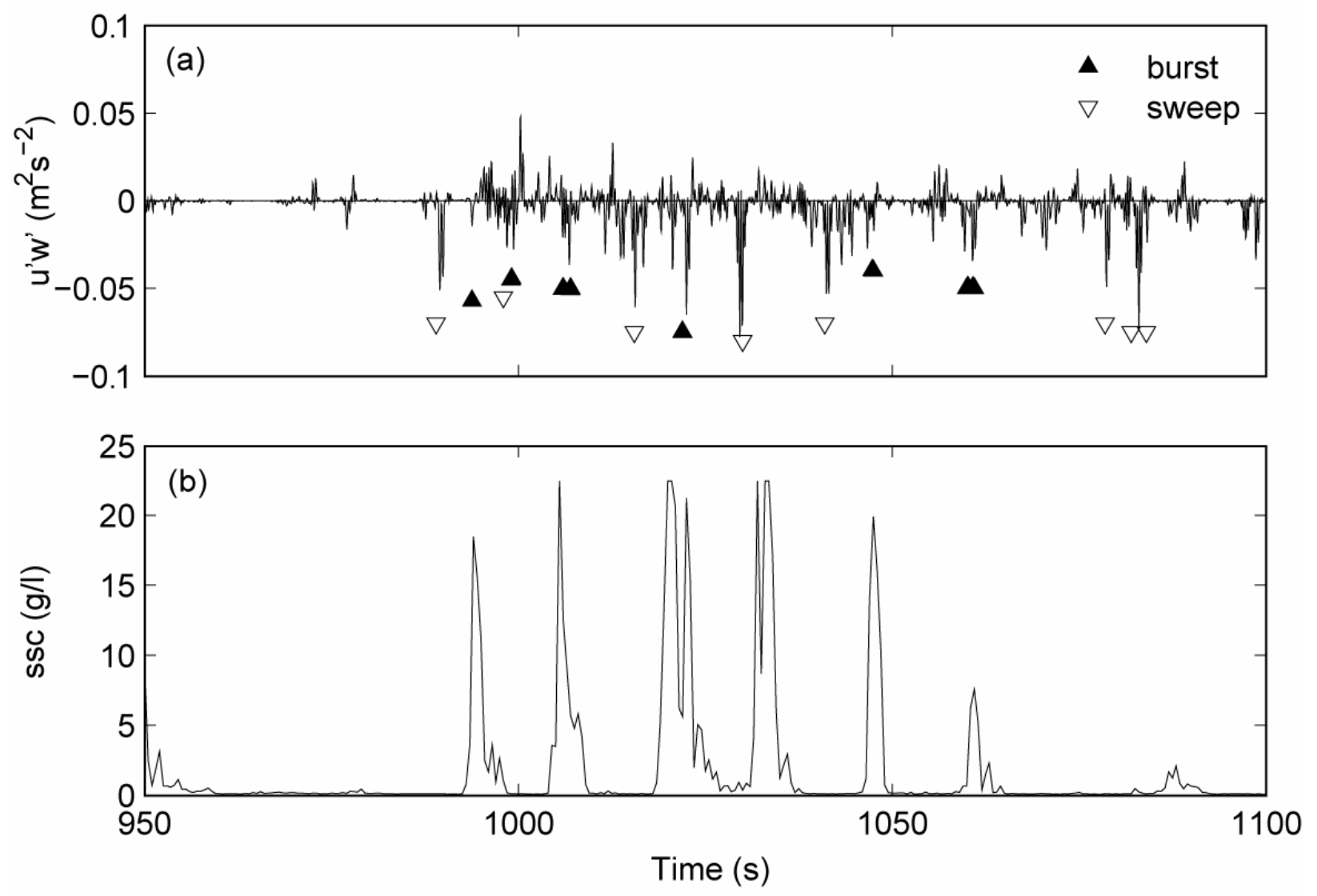

Figure 10. Time series records of: (a) turbulent Reynolds stress ( $\left.u^{\prime} w^{\prime}\right)$; and (b) suspended sediment concentration (sSc) between 950 and $1100 \mathrm{~s}$. 